\title{
Arquivos e decolonialidade: breves considerações acerca de uma abordagem necessária em pesquisa e extensão
}

Archives and decoloniality: brief considerations towards a necessary approach on research and extension

\section{Resumo}

Igor Gak ${ }^{1}$

Nycole Toseli ${ }^{2}$

Andressa Sousa da Costa ${ }^{3}$

Anna Carolina Araujo Chipoco ${ }^{3}$

Nosso objetivo é apresentar reflexões tecidas durante o último ano no contexto de reformulação das ações do projeto "Arquivos e Direitos Humanos em Perspectiva Global". Procuramos explorar as contribuições que a abordagem decolonial pode oferecer para os estudos e a prática arquivística na contemporaneidade. Propomos entender os arquivos como entidades formadoras de subjetividades que podem reforçar ou romper "padrões coloniais de poder". Como método de trabalho, mapeamos preliminarmente arquivos cuja constituição e atividades podem ser lidas como estratégias de rompimento dessa "lógica da colonialidade". Três destes acervos são apresentados aqui: o IPEAFRO, o Arquivo Dona Orosina Vieira e o LabJaca, analisados de acordo com a perspectiva decolonial.

Palavras-chave: Arquivologia. Pensamento Decolonial. Direitos Humanos. Arquivos.

\section{Abstract}

Our aim is to present preliminary thoughts that we have been weaving over the last year by reformulating the goals of the project "Archives and Human Rights in a Global Perspective". We seek to explore the contributions that a decolonial approach can offer to the contemporary archival studies and practice. We propose an understanding to the archives as subjectivity-shaping entities that can reinforce or break the so called "colonial matrix of power". As a working method, we preliminarily mapped archives whose constitution and activities can be read as a program for breaking this "logic of coloniality". Three of these collections are presented here: the IPEAFRO, the Dona Orosina Vieira Archive and the LabJaca, viewed under an decolonial lens.

Keywords: Archival Studies. Decolonial Thought. Human Rights. Archives.

\footnotetext{
${ }^{1}$ Docente do Departamento de Arquivologia da Universidade Federal do Estado do Rio de Janeiro (UNIRIO) - igor.gak@unirio.br

2Discente do curso de Arquivologia da Universidade Federal do Estado do Rio de Janeiro (UNIRIO) bolsista PIBEX - nycoletoseli@edu.unirio.br

${ }^{3}$ Discentes do curso de Arquivologia da Universidade Federal do Estado do Rio de Janeiro (UNIRIO) andressa@edu.unirio.br; carolchipoco@edu.unirio.br
} 


\section{RAIIZESE RUMOS

\section{Introdução}

Este texto apresenta as reflexões que fizemos no âmbito do projeto "Arquivos e Direitos Humanos em Perspectiva Global" durante o último ano. Nosso objetivo é estimular o conhecimento e interesse dos estudantes de Arquivologia por ações de promoção e defesa dos Direitos Humanos. Diante das condições restritivas impostas pela pandemia de Covid-19, empreendemos uma reformulação das ações pretendidas em nosso projeto. Decidimos dedicar-nos a uma perspectiva ainda pouco explorada nos debates arquivísticos brasileiros: as possibilidades que a abordagem decolonial oferece para os estudos e a práxis arquivística. Buscas em bancos de periódicos nacionais retornaram apenas um artigo que se propunha a refletir sobre as contribuições do pensamento decolonial para a Ciência da Informação (RIGHETTO, KARPINSKI, 2021). Essa ausência de estudos na Arquivologia indica um campo a ser explorado e que pode contribuir para inserir ainda mais a pesquisa arquivística nos debates sociais e políticos da atualidade.

Uma abordagem decolonial da práxis arquivística corresponde a pôr em evidência personagens, grupos e práticas socioculturais historicamente alijados das esferas de poder. Nesse sentido, propomos um deslocamento do olhar para perceber as possibilidades narrativas e de formação subjetiva que esses aspectos ensejam. Isso quer dizer que buscamos concentrar nosso olhar sobre as "narrativas tácitas" (KETELAAR, 2001) presentes na constituição dos acervos, nos usos e reusos da informação, numa perspectiva que nos permite identificar a interação entre a comunidade e o arquivo.

Desenvolvemos um levantamento que nos permitiu identificar alguns arquivos que, pelas práticas de constituição de acervos, acesso e relação com a comunidade devem ser analisados sob essa perspectiva. O primeiro deles é o arquivo do Instituto de Estudos e Pesquisas Afro-Brasileiros (IPEAFRO), cujo acervo é um retrato das ações do ativista Abdias do Nascimento (1914-2011). O segundo é o Arquivo Dona Orosina Vieira (ADOV), localizado no Complexo da Maré, conjunto de 





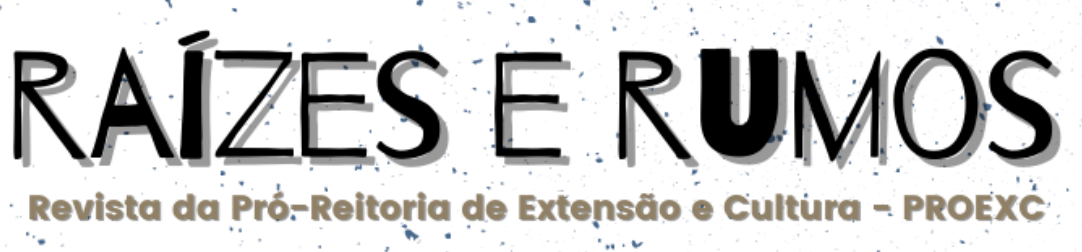

- ISSN: 2317-7705 online ISSN: 0104-7035 impresso

(APPADURAI, 2003, p. 25, tradução nossa). E desde a sua criação, o arquivo do IPEAFRO constitui-se num importante agente na luta política pelos direitos da população negra brasileira e pela valorização identitária desse grupo.

\subsection{Arquivo Dona Orosina Vieira (ADOV)}

O Arquivo Dona Orosina Vieira está situado no Museu da Maré, instituição cultural do Complexo da Maré, comunidade da Zona Norte do Rio de Janeiro. O acervo é constituído por uma documentação fora do padrão daquelas que normalmente constituem instituições de memória. Formam o conjunto, essencialmente, objetos relacionados às memórias dos moradores, isto é, documentos de tipo iconográfico, textual ou audiovisual que eles próprios identificam como representativos da memória da comunidade. Seu acervo, portanto, não é constituído de documentos públicos gerados para cumprir funções administrativas, imbuídos de valor histórico após um criterioso processo de seleção. Aqui, a prática de arquivar se constitui numa "prática radical" (BALATBAT-HELBOCK et al., 2018, pp. 154-155), que considera a interpretação e avaliação dos moradores como critérios fundamentais de seleção e constituição da memória. Nesse sentido, o arquivo oferece um espaço para documentar histórias silenciadas, contadas através do próprio olhar dos moradores.

Esse método permite ao arquivo romper a narrativa oficial, exterior à comunidade, sobre o surgimento e crescimento da comunidade, a história de vida dos moradores e as práticas culturais, políticas, econômicas e epistêmicas próprias da favela. Esse é um exercício de ressubjetivização e de valorização identitária num contexto em que a violência do Estado sobre a comunidade é justificada por um discurso que identifica esse espaço, as pessoas que nele habitam e sua cultura como algo a ser combatido.

Se reconhecermos que os arquivos tradicionais são incapazes de dar voz aos silenciados (BASTIAN, 2006, p. 284), uma vez que refletem estruturas de dominação fundamentadas na exclusão e no silenciamento, o ADOV assume um protagonismo determinante na formação da identidade dos moradores da Maré. O próprio nome do 




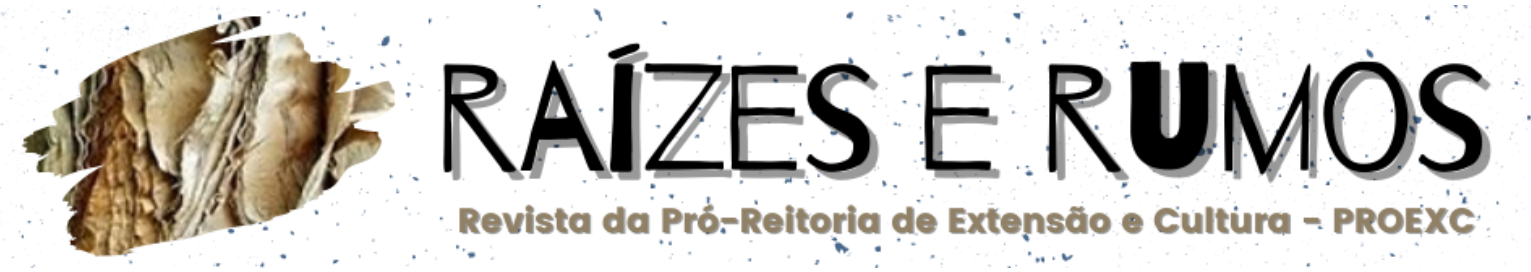

não apenas as ações desses arquivos, mas também as potencialidades analíticas presentes na relação estabelecida entre a comunidade e o arquivo.

\section{Referências}

APPADURAI, Arjun. Archive and Aspiration. In: BROUWER, Joke, MULDER, Arjen, CHARLTON, Susan (Org.). Information is Alive: Art and Theory on Archiving and Retrieving Data. Rotterdam, New York: V2/NAi Publishers; D.A.P./Distributed Art Publishers, 2003, pp. 14-45.

BALATBAT-HELBOCK, Lynhan, et al. Colonial Neighbours: ein partizipatives Archivprojekt von SAVVY Contemporary. In: KNOPF, Eva, LEMBCKE, Sophie, RECKLIES, Mara (Org.). Archive dekolonialisieren: Mediale und epistemische Transformationen in Kunst, Design und Film. Bielefeld: Transcript, 2018, pp. 151162.

BALLESTRIN, Luciana. América Latina e o giro decolonial. In: Revista Brasileira de Ciência Política, n 1, 2013, pp. 89-117.

BASTIAN, Jeannette Allis. Reading Colonial Records Through an Archival Lens: The Provenance of Place, Space and Creation. In: Archival Science, 6: 3-4, 2006, pp. 267-284.

BOATCĂ, Manuela. Postkolonialismus und Dekolonialität. In: FISCHER, Karin, HAUCK, Gerhard, BOATCĂ, Manuela (Org.). Handbuch Entwicklungsforschung. Wiesbaden: Springer VS, 2016, pp. 113-123.

KETELAAR, Eric. Tacit narratives: The meanings of archives. In: Archival Science, 1: 2, 2001, pp. 131-141.

MIGNOLO, Walter D. The Darker Side of Western Modernity: Global Futures, Decolonial Options. Duke University Press, 2011.

PINTO, Julio Roberto De Souza, MIGNOLO, Walter D. A modernidade é de fato universal? Reemergência, desocidentalização e opção decolonial. In: Civitas - Revista de Ciências Sociais, 15: 3, 2015, pp. 381-402.

RIGHETTO, Guilherme Goulart, KARPINSKI, Cezar. For a decolonial social epistemology. In: Transinformação, 33, 2021. 